\title{
Algunas notas sobre la dimensión biopolítica de la comunicación ${ }^{1}$
}

\section{Some Notes on Communication Biopolitical Aspects}

\author{
Andrea Miranda \\ Universidad de Chile \\ andreamirandameza@gmail.com
}

\begin{abstract}
Resumen
El presente artículo busca demostrar el modo en que los medios de comunicación se articulan bajo un régimen de poder biopolítico, siendo como punto de referencia la siempre problemática relación entre vida-comunicación y política. Bajo esta óptica de pensamiento, conviene recordar la intervención del cuerpo como escenario de poder y las profundas mutaciones del cuerpo en el desarrollo tecnológico. Las nuevas tecnologías de la comunicación e información representan una transformación antropológica y nuevos regímenes de significación, que operan bajo una percepción del poder no localizable desde el punto del cual irradia, sino disperso y transversal, que se hace efectivo en lo cotidiano como lugar.
\end{abstract}

Palabras clave: comunicación, cuerpo, política, vida cotidiana, poder.

\begin{abstract}
This article tries to show the way how the media articulates under a biopolitics power regime, taken the troubled relation life-communication-politics as a point of reference. It is convienent to remember body intervention as power issue and the important body mutation in the technological development. New communication technologies and information represent an antropologic transformation and new significance regimens. Where power perception does not seem to appear already located in a place where it irradiates, but dispersed and transversal, which is effective in daily as a place.
\end{abstract}

\footnotetext{
${ }^{1}$ Este artículo pertenece a la tesis Concepto de biopolitica: críticas y aportes claves para un pensamiento del presente para optar al grado de Magíster en Comunicación Política del Instituto de la Comunicación e Imagen. Universidad de Chile.
} 
Keywords: communication, politics, body, daily life, power.

\section{Introducción}

"La esencia de lo tecnológico no es algo técnico sino el modo como el hombre se produce a sí mismo."

Heidegger

Podríamos afirmar que están ocurriendo ciertas mutaciones de los modos de significación de las nuevas tecnologías de la comunicación. Estas son especialmente observables en el contexto de las re-significaciones tecnológicas y culturales de la globalización informacional.

$\mathrm{Si}$ entendemos estos cambios como un proceso modernizador en la historia, podríamos ver e incluso, más originariamente, reflexionar sobre cómo la vida se articula a través de dos procesos: la hibridación orgánico-tecnológico del cuerpo y su representatividad eminentemente discursiva.

Se traduce así, una nueva apertura interpretativa sobre el cuerpo, que sugeriría identificar los rasgos que cruzan y modelan sus movimientos y técnicas en clave política. Es preciso confesar que, sobre la vida y sus múltiples relaciones, recaen los mecanismos que represivamente ejercen dominio sobre los hombres, detectándose sobre la vida misma, la plasmación y las condicionantes que posibilitan ciertos regímenes de politicidad.

Resulta interesante tomar en cuenta respecto, a este punto, una preliminar reflexión sobre la dimensión biopolítica de la comunicación que estamos ciertos no es suficiente, ya que algunas tensiones en sus propuestas merecen una mirada más atenta. Nuestra atención va destinada a concebir una ruta de inspección, un desciframiento sobre el campo de la comunicación en el tiempo presente. Este primer acercamiento nos traslada hacia nuevas formas de pensamiento. ¿Es posible ubicar un paradigma biopolítico de la comunicación?, ¿cómo se traduce lo biopolítico en su carácter comunicacional? Con esto no pretendemos resolver todos los problemas que implica nuestro eje de acción principal, sino más bien, abrir posteriores debates en torno al tema. ¿Alguna vez la comunicación no fue biopolítica? o ¿cómo se presenta una política vaciada de contenidos frente a una tecnología con más capacidad de reflexión?

Las nuevas tecnologías de la comunicación e información reclaman una nueva mirada y estructuras de significación sobre los escenarios sociales, relaciones de poder y contextos políticos. Desde luego esto arrastra nuevas demandas de sociedades portadoras de una humanidad unida, aunque al mismo tiempo de una humanidad reducida a una 
uniformidad. Una nueva producción de cuerpos en la esfera de lo virtual que circula por la vida cotidiana. Ambas perspectivas convergen en un contexto político, en un proyecto histórico que plantea el capitalismo mundial, por esta razón, lo que se pone en juego son nuevos registros de racionalidad y un ofrecimiento tecnológico que tiende a crear un nuevo ambiente humano, una transformación que se aloja en una visibilidad cultural del sujeto como ente generador de procesos comunicativos.

\section{Bio-política: la vida como objeto de poder}

Desde un punto de vista teórico podríamos distinguir algunos momentos significativos para la reflexión del concepto de biopolítica. Así, podemos situar ciertas categorías y sucesos que corresponderían a un tipo histórico de circunstancias y acontecimientos político-filosóficos. Por tal, proponemos levantar un primer acercamiento desde la perspectiva de la filosofía política, concretamente en relación con las distintas ideas sobre los contenidos biopolíticos y comprensiones sobre la vida biológica. Una primera aproximación se sitúa en el pensamiento de Foucault, quien nos traslada a un punto esencial: la reflexión sobre la vida y lo vivo como un conjunto de fuerzas, si bien la vida resulta ser substancial en sus análisis, también lo es la vida como objeto de poder, y la forma en la cual la vida se resiste y en este resistir crea nuevas formas de comportamiento.

En la última lección del libro Genealogía del Racismo, Foucault (1992) reflexiona en relación a si la vida, en tanto que razón primera, originaria y fundamental del contrato, no debería estar excluida del mismo. Se expresa entonces, cómo el problema de la vida empieza a problematizarse en el campo del análisis del poder político. El autor plantea que el control de la sociedad sobre los individuos no se operó simplemente a través de la conciencia o de la ideología, sino que se ejerció también en el cuerpo y con el cuerpo.

Para la sociedad capitalista lo más importante era lo biopolítico, lo somático, lo corporal. La "metáfora organológica" es el eje central de la política, la enfermedad está en el centro de la metáfora. El cruce entre saber político y saber médico está constituido por el problema en común de la conservación del cuerpo. Una tratadística jurídico-política que vuelve a hablar el lenguaje del cuerpo, otra vez la teoría política deriva de las ciencias de la vida y en especial de la medicina. (Esposito, 2002, p. 193)

\footnotetext{
${ }^{2}$ Por este motivo Esposito confiere que la categoría de soberanía cede lugar a la inmunización o, cuando menos, se entrelaza con ella. Este es el procedimiento general dentro del cual se produce el cruce de política y vida.
} 
De esta forma, se establece la noción de policía estará a cargo de la organización de la sociedad como medio de bienestar físico de salud óptima y de longevidad, lo que conlleva una policía general de la salud.

Por otra parte, Agamben propone que el pensamiento es "forma-de-vida" (2001, p. 20). Según el autor un concepto-guía y el centro unitario de la política que viene. La tesis general de Agamben es que el sentido y las consecuencias históricas de la política moderna deben aprehenderse a partir de la reducción de la vida humana a mera vida abandonada, esto es una realidad in-significante necesitada de ser formada por la política.

Así, el estado de excepción es -ante todo- una zona ajurídica donde el hecho y el derecho, el afuera y el adentro, la exclusión y la inclusión, entran en una zona de absoluta indiferenciación.

Agamben (1998, p. 176) siguiendo a Arendt sostiene que la posición originaria del hombre como nuda vida, significa que toda valoración y toda politización de la vida, deja de ser políticamente relevante, y no es ya más que "vida sagrada" y como tal, puede ser eliminada impunemente.

La violencia se presenta protagónica de los hechos más relevantes de la política moderna y a su vez, como el hecho mismo mediante el cual el hombre pasa a formar parte de los dominios del hombre. En este sentido Arendt aclara:

\begin{abstract}
Ni la violencia ni el poder son un fenómeno natural, es decir, una manifestación del proceso de la vida, sino más bien pertenecen al terreno político de los asuntos humanos. El poder, como mando de dominación, el instinto innato de dominación y de una innata agresividad del animal humano, cae en la convicción eterna de ¿quién manda a quién? Si la política es necesaria para la subsistencia de la humanidad no puede estar ausente también la noción de autoaniquilamiento, ya que, la política ha perdido su deriva, su horizonte y solo se ha vuelto falta de sentido. (2005, p. 90)
\end{abstract}

Nos encontramos en los territorios o dominios donde circula la violencia como un secreto deseo de muerte sobre la especie humana. Vivimos en una paz que no permite que suceda nada que haga imposible una guerra, lo que representa uno de los pecados mortales de la política en la Edad Moderna. La política ha de poner a salvo a la vida misma, inmunizándola de los riesgos que la amenazan de extinción. Como sostiene Esposito en Immunitas: Protección y negación de la vida: "Lo que parecía una relación de dos términos política y vida debe interpretarse como un juego que incluye un tercer término, la inmunización de la política" (2005, pp. 160-161). Así, el cuerpo es el lugar privilegiado para el despliegue de la vida, también es donde más se advierte la amenaza de la muerte. La clave de este pasaje reside en una creciente complicación de la relación entre la vida y el cuerpo político. La inmunización se extendió progresivamente desde los ámbitos del 
derecho, al ámbito de la política, la economía, la cultura y las nuevas tecnologías de la información hasta asumir el rol de paradigma general de la modernidad.

Por último, es importante situar la vida como objeto de poder en relación a los nuevos procesos de producción mediante las tecnologías de la comunicación, los cuales proceden de la necesidad de poseer el cuerpo en su sentido más general. Esto significa tomar el cuerpo en sus intenciones y voluntades.

Esta dominación técnica tiene un reconocimiento instantáneo en nuestra sociedad, hasta el punto en que ya no se puede operar sin ella, de aquí se deduce su autoridad y legitimidad política. Esta donación del cuerpo en su instantaneidad, aumenta la posibilidad de re-producirse y lo hace ver como una nueva forma de ocupación del poder, supuestamente capaz de administrar la vida en todas sus formas, pero a su vez, anulado de toda promesa. En este sentido podríamos decir, que el mismo capitalismo — en sus facultades o propiedades discursivas - aniquila toda reflexión de una idea de democracia.

\section{Los medios de comunicación se articulan bajo un régimen biopolítico}

Nuestra primera tarea será demostrar el modo en que los medios de comunicación se articulan bajo un régimen de poder biopolítico. Una perspectiva que bien pudiera interesarnos a la hora de pensar la siempre problemática relación comunicación, cuerpo, política. Lo que esa ambigua y contradictoria relación nos plantea es la imposibilidad de seguir atribuyendo una teoría social incapaz de aceptar la dinámica propia de los procesos comunicativos. El deslinde de las nuevas cuestiones que acarrea la configuración de un campo y el de la comunicación como biopolítica es justamente la mutación del cuerpo atravesado por la lógica mercantil. El cuerpo humano ha sido siempre un producto social, se conforma en una naturalidad que sigue siendo "artefacto".

El cuerpo resaltado por los medios de comunicación puede dar cabida no solamente al cuerpo disciplinado, sino también al cuerpo simulado cuya eficacia se visualiza en materialidades a nivel político y económico, pero también tecnológico.

Los dispositivos biopolíticos de la comunicación desarrollan una nueva percepción del poder sobre el cuerpo, que no aparece ya localizado en un punto desde el cual irradia, sino disperso y transversal, una nueva valoración de lo local en cuanto espacio de la proximidad. Esto es donde se hace efectiva la diferencia y donde se despliega lo cotidiano como lugar.

A este respecto, podríamos agregar que estamos frente a una dinámica de interacción mucho más compleja, tanto en términos de los actores como del espacio productivo, de la recepción, y de las dimensiones posibles de análisis. Nos salimos de la teoría de la comunicación e incorporamos filosofía, antropología, historia, economía y una semiótica 
mucho más ligada a la teoría de los discursos cuya racionalidad, discursividad, eventualidad, efectos y estructuras, se presentan en la naturaleza cotidiana de la vida. Tal como sostiene Eduardo Santa Cruz:

Lo que llamamos realidad cotidiana, es un continuo desplazamiento e interacciones entre los diversos mundos que habitamos. En principio, nuestra cotidianeidad se desenvuelve en una pluralidad de mundos, estableciendo lazos más o menos estrechos con cada uno de ellos; desde el universo físico al universo social, histórico y subjetivo.

El saber ocupa un espacio en lo cotidiano, lo corporal constituye un terreno para explorar conexiones discursivas, las cuales han participado en la adopción o rechazo de las conductas sociales. Lo que hace Foucault en el marco de sus desarrollos sobre discurso, saber y poder, es justamente detectar y analizar esta incidencia sobre el cuerpo, que caracteriza de la siguiente manera: "A este conjunto de elementos formados de manera regular por una práctica discursiva y que son indispensables a la constitución de una ciencia, se les puede llamar saber" (2005, p. 306).

Hoy en día los medios de comunicación pretenden traspasarnos la vida cotidiana tal y como discurre, lo que de alguna manera trata de convertirse en espejo, deformante en cierto aspecto, de todos los niveles de conflictividad cotidiana.

Es preciso entonces, evidenciar la constante intervención del cuerpo como escenario de poder, cuya inquietud principal recae sobre procesos microscópicos de relaciones, que suponen de la manera más inmediata una escena dentro de la cual se manifiestan campos de discursividades que configuran un cuerpo mediatizado.

Tal como advierte Juan Pablo Arancibia:

La videósfera y la mediatización no serían el régimen de supresión del mundo, sino que sería la escritura y producción del mundo como régimen circuital de visibilidades y velocidades tejidas como un campo general de subjetividades. Así, más que levantar el ingenuo reclamo por una corporeidad real, quizá pudiéramos atender al proceso de escritura y producción de un cuerpo mediatizado. (2005, p. 125)

Bajo estas circunstancias hay, desde luego, una articulación del modelo de sociedad en el que los actores sociales producen el campo de la comunicación. Desde este ángulo, nos atreveríamos a decir que los medios de comunicación, al repetir estos rituales cotidianos, han logrado convertirse a su vez, en modelos de comportamiento social y político. Esta revolución de los medios de comunicación no puede representarse como antes, ni escribirse y leerse como antes, ya que las nuevas tecnologías definen un nuevo régimen de discursividad, por tanto, de saber. "Todas las tecnologías tienden a crear un nuevo ambiente humano, las tecnologías no son simplemente inertes contenedores de seres 
humanos, son procesos activos que remoldean igualmente los seres y las otras tecnologías" (Renaud, 1990, p. 146).

Si bien el problema central de la dimensión biopolítica de la comunicación es el cuerpo y sus ramificaciones hacia lo político y lo cotidiano, hay que detectar al menos cinco categorías dignas de ser revisadas:

Primero, el énfasis de una mutación socio-histórica sobre el discurso de los hombres y propia del estadio del desarrollo tecnológico entrega propuestas que remarcan la encarnación de las nuevas formas ultrarrápidas de control al aire libre y reemplazan a las viejas disciplinas que operan en un sistema cerrado, una pieza cuyos resortes procuran comprender las superficies y las interfases del poder. Estas tendencias construyen nuevos artefactos y significaciones que amplían el universo discursivo en virtud de la teoría comunicativa.

Segundo, la intensificación del paradigma inmunitario, o lo que podríamos llamar la apropiación política de la vida que nace de la ligazón entre; vida y poder, economía política y dispositivos de seguridad.

Tercero, el cuerpo, el cual se articula y desarrolla en la vida cotidiana encarnado así la discusión biopolítica contemporánea. El cuerpo hoy en día está para alimentar el imperativo categórico de seducción y en ese sentido el cuerpo se articula como objeto y sujeto del espacio político.

Cuarto, la relación entre la Mediatización de la subjetividad y la Vida cotidiana, ocurre en y sobre los cuerpos como pautas de producción y reproducción de socialización en la superficie de lo mediático.

Cinco, la consagración de la Economía de mercado y la Democracia liberal, el tardocapitalismo como lógica mercantil tanto en las esferas de lo político y de lo cultural. Nos enfrentamos a una constante relación del sujeto hacia una orientación mercantil dentro de una comunidad política moderna. O lo que en palabras de Lipovetsky podríamos denominar un capitalismo libidinal (Cuadra, 2003, p. 38). O bien, al decir de Fromm: "Todo el mundo es una mercancía para todo el mundo (...) Las sociedades contemporáneas modeladas bajo la impronta del consumo, han establecido fines y legitimidades fundadas en relaciones de seducción" (Cuadra, 2003, p. 38).

\section{El paradigma de lo biopolítico en su carácter comunicacional: una transmutación corporal}

Este panorama de las nuevas tecnologías de la comunicación se presenta como un paso adelante en la misma dirección de la liberación de las limitaciones corpóreas (Bettettini y Fumagalli, 2001, p. 105). Las posibilidades que tienen estos sistemas, son vistas también 
desde la perspectiva de liberación del sometimiento a un espacio limitado, un espacio más allá de cualquier limitación de las distancias. La corporeidad es, por un lado, recuperada en la comunicación a distancia y por otro, es trascendida a través de la asunción de un cuerpo virtual más manipulable que el real. Así, los viejos regímenes de temporalidad son producto de una profunda mutación. Lo que contempla una vida reducida al sometimiento tecnológico, a saber: Blogs, Fotolog, My space, Facebook, etc.

Desde una perspectiva corporal implica la posibilidad de estar presente en diferentes sitios al mismo tiempo. Multiplicar la presencia de los cuerpos que no se reducen -al comienzo ni al final de la piel ni a los organismos - sino que producen ese efecto de frontera, es decir, que se encuentran siempre en el entre y nunca en los extremos.

En lugar de desvanecerse en la inmaterialidad del aire, el cuerpo se está complicando, replicando y escapando a su organización formal. En nuestros días los individuos ya pueden participar en el universo virtual - bien de modo episódico o bien de un modo más recurrente - que genera un compromiso para dar lugar a distintos modos de expresión, como el activismo militante del ciberespacio, los cuales constituyen modos de acción política en el nuevo entorno. El ciberespacio como espacio rizomático ${ }^{3}$ permite un intercambio discursivo y conversacional ilimitado, debido tanto a la instantaneidad como la interactividad del medio cibernético. Las transformaciones tecnológicas, derivadas a partir de la compleja interacción ciencia-técnica, influyen de modo decisivo en el modo en que interpretamos el mundo, la sociedad y a nosotros mismos.

Las nuevas tecnologías sirven de polo infraestructural a una suerte de inteligencia colectiva que introduce un metacambio en el dominio comunicacional cuya singular dinámica virtual se está haciendo a cada instante. La nueva modalidad comunicacional se transforma en un nuevo régimen de significación (Cuadra, 2003, p. 63).

\section{Docurreality médico: entre la televisión, la tecnociencia y el hombre prótesis}

Programas como: Doctor Vidal, Cirugía de cuerpo y alma y Vida: Radiografía de un cambio, son enmarcados dentro de la categoría de docurreality médico. Aquí encontramos la manifestación más clara de lo que hace algunos años escribiera Baudrillard acerca de la generalización de la teoría de McLuhan sobre las extensiones del hombre. Baudrillard es crítico del optimismo y de la universalización respecto de las extensiones mediatizadoras de McLuhan, por lo tanto, establece su propia teoría: "Todo lo del ser humano, de su

\footnotetext{
${ }^{3}$ Deleuze y Guattari rechazan la división dicotómica de naturaleza metafísica "interioridad/exterioridad", propia de un sistema organizado y estable y advierten que los nuevos modos de producción social como los nuevos sujetos políticos sólo se pueden entender y darse en una estructura abierta, fluida, desjerarquizada y caótica que se denomina rizoma.
} 
cuerpo biológico, muscular, animal, ha pasado a las prótesis mecánicas" (1989, p. 28). De ello se deriva la necesidad de situar el cuerpo en el centro de la cuestión mediática, la tele (presencia), el dispositivo tele, reemplaza el espacio público por la imagen pública. Así la televisión expone y establece un vínculo entre las prácticas biomédicas y el cuerpo prótesis.

La pantalla televisiva generaliza fenómenos con las experiencias más inéditas, donde coexisten historias reales de gente común que busca dar un giro a su vida a través de la cirugía plástica y reconstructiva. La introducción artificial de micro-objetos técnicos en el cuerpo, nos da a entender que la técnica, hoy en día, coloniza el cuerpo del hombre como ha colonizado el cuerpo de la tierra. Llegamos de esta manera a convertirnos en el prototipo de lo que Virilio alguna vez llamó: "hombre- prótesis" (1999, p. 56). El cuerpo se somete bajo la obligación de un envite artificial-técnico. Así, el pacto que se produce entre la pantalla televisiva y el sujeto se visualizar a través del canal de la observancia ritualizada en la potencia estética.

La tecnología invade nuestro cuerpo y lo mejora, o al menos lo modifica a nuestro gusto y abre las posibilidades de variar lo que de forma natural nos ha sido dado. Dentro de tales descripciones aparece el hombre como el más terrorífico técnico sobre lo humano. En este sentido Jean-Luc Nancy sostiene:

El hombre comienza a sobre-pasar infinitamente al hombre (...) se convierte en el más terrorifico y perturbador técnico, como lo designó Sófocles hace veinticinco siglos, el que desnaturaliza y rehace la naturaleza, el que recrea la creación, el que la saca de la nada y el que, quizá, vuelva a llevarla a la nada. El que es capaz del origen y del fin. (2006, p. 44)

La inmunidad no es únicamente la relación que vincula la vida con el poder; sino el poder de conservación de la vida (Esposito, 2006, p75). Más que un elemento entre otros, más que un corte localizable se trata de entender que la política no es sino posibilidad o un instrumento para mantener con vida la vida. Al hablar del ámbito biomédico también nos referimos a la condición refractaria de un organismo vivo, ya sea de forma natural o inducida. Por cierto, estamos hablando de una técnica aplicada a la vida, pero en una forma que pretende modificar su desarrollo espontáneo.

\section{La TV en su dimensión lúdica y de placer}

Ciertamente, ver televisión como una actividad humana significa enraizarla en la naturalidad de la vida. Este apetito por la televisión resulta especialmente observable por el intercambio entre el emisor permanente de espectáculos y mensajes que conviven con todos los miembros del hogar y que al mismo tiempo funciona como una ventana abierta 
al mundo que permite a la persona asistir en directo a una multiplicidad de hechos y situaciones (Giordano, 1999, p. 20). Así, la televisión se instaura también como temática preferente y recursiva del diálogo cotidiano, entre el individuo y su medio familiar, escolar y laboral. La televisión es aparato industrial en cuanto fenómeno discursivo y espectacular.

En este escenario el espectador televisivo es protagonista del paso que constituye la coartada social de la instauración de un espectáculo permanente (Giordano, 1999, p. 54). En nuestro país existen diversos programas dedicados a hablar simplemente de la farándula como fenómeno comunicacional. A saber: Sálvense Quien Pueda, Mira Quién Habla, Primer Plano, Intrusos, Alfombra Roja, etc.

Aquí resucitan los esquemas impuestos por una superficie seductora, donde brillan de forma intermitente redes de imágenes ritualizadas bajo sonrisas que metaforizan un inmenso proceso de signos de fascinación, encarnada en la figura de ídolos televisivos. La farándula se transforma en un nuevo régimen de visibilidad, una especie de utensilio cotidiano donde el hombre se transforma en un objeto de aparición. El sujeto productor del discurso se transforma en un producto más de la TV donde debe desarrollar una simulación de su vida diaria y entregarla al gran público.

Al decir de Rancière esto es:

En primer término la lógica estética de un modo de visibilidad que por una parte revoca las escalas de grandeza de la tradición representativa y por otra parte revoca el modelo oratorio de la palabra en favor de la lectura de los signos existentes sobre los cuerpos de las cosas, los hombres y las sociedades. (2002, p. 20)

La televisión en su lenguaje hace dóciles los cuerpos, les exige y los obliga a imponerse como una especie de red de sociabilidad que captura la audiencia. Una narratividad que tiene como punto de partida la superación de la barrera del anonimato y la necesidad de pronunciarse. Este hecho logra establecer una verdadera relación nupcial con el otro.

Es decir, logra colocarse en la dimensión de lo verdadero por su propia ausencia a través de la representación de un hombre atmosferizado por la omnipresencia de la pantalla de TV, dispensando su "cuerpo propio" por el "cuerpo imagen": un espacio de seducción por la atracción al vacío. De esta forma se ensamblan nuevos registros de la estética configurando un discurso donde convergen el maquillaje y situaciones teatralizadas en sí mismas.

Estamos frente a un régimen que podríamos denominar escópico, una especie de cordón umbilical que liga al espectador con el espectáculo televisivo: "la televisión es un artefacto en el que hay siempre alguien mirándome” (González Requena, 1999, p. 106). Perfecto acoplamiento para una economía mercantil y del deseo. En el curso de esta reflexión, perfectamente conocida en la esfera social-cotidiana, la farándula y sus 
personajes televisivos logran transformarse en un tipo de discurso sobre la identidad social naturalizada bajo el clásico ejemplo del discurso que suscita un cuerpo-para-el-otro.

Desde este ángulo, se vuelve visible otro rasgo decisivo: la difusión de la feminidad y masculinidad. Nos referimos a los modelos -esta vez físicos- ofrecidos por los "guapos" de la sociedad. Acá aparece el look, la imagen, cotizarse en el mercado visual, ser imagen seductora, ser deseado por la mirada del otro. Y así, el espectáculo televisivo ha construido un universo publicitario plenamente imaginario y narcisista, de cuerpos y objetos light/look donde toda huella de lo real es insistentemente borrada.

Es aquí donde aparece la figura del hombre común o nuevo héroe de lo cotidiano. En este sentido nos explica Álvaro Cuadra: "Todo hombre es héroe de su propia vida, y por ende susceptible de ocupar su lugar en la pantalla". La televisión hace visible la individualidad; la individualidad se hace visible por la heroización.

Aquí lo que se juega es lo que Baudrillard denominó: estrategias de las apariencias (Baudrillard, 1989, p16). Hacer girar las apariencias sobre ellas mismas, significa hacer actuar al cuerpo como pura apariencia y no como profundidad de deseo.

En efecto, la exhibición de los sentimientos se ha transformado en una mercancía preciada para todos los programas de televisión, una grave pérdida de intimidad, una especie de enfermedad derivada de conflictos individualistas que toman elementos típicos de la vida cotidiana. Podemos darnos cuenta de que tanto la conquista como el rechazo, son solamente un tipo de adorno más al programa, todo se transforma en ornamento puro, formado en un espacio de seducción.

Así, el cuerpo se transforma en una red intercorpórea de reenvíos a través de la mirada con el receptor de televisión. De esta manera, el espectador termina viviendo la propia vida como si estuviera participando de un espectáculo. Las sociedades actuales sólo se perciben a sí mismas a través de símbolos mediáticos de masas, discursos, modas, programas y personalidades famosas. Una especie de retratismo del mundo con chispas de realidad, que conviven en el cuerpo mismo y la continua exhibición de su presencia.

Por otro lado, el esquema de vigilancia y castigo parece aplicarse a la ideología de la belleza femenina, ya que mantiene el poder para controlar cierto disciplinamiento sobre el cuerpo donde la dieta y el ejercicio logran hacerlos más dóciles. La figura femenina se torna protagónica como agente de consumo, patentizado en la moda. Aquí ya no se trata de que el cuerpo sea visto o no visto, la idea es que ahora sea posible verlo -o dar a ver el propio- en su gracia y en su vigor.

Este es el motivo por el cual el cuerpo bajo los mecanismos de cosmética y cirugías, logra proyectarse como una superficie siempre expuesta a la mirada de los otros, por vía perceptiva, olfativa y táctil. "En el caso de los jabones, las cremas y los polvos, (uso externo) el cuerpo es tratado como una superficie (reposan sobre la piel) mientras que en los otros (uso interno) el cuerpo es tratado como un hueco" (Traversa, 1997, p. 85). La 
regulación del darse a ver, ser visto y, finalmente, construir un verdadero dispositivo del régimen de miradas y los atuendos que las propician, constituye un núcleo central de la organización del cuerpo en la publicidad.

\section{Normas, disciplinamiento y castigo}

Un ejemplo del paso del panóptico al sinóptico es el de Cuestión de peso. En él, se muestra en qué formas se combinan hoy día la sociedad disciplinaria -en la que hay que esforzarse por conseguir lo que se desea- con la sociedad del consumo y del placer. Este tipo de programas explota la tensión entre dos componentes: por un lado, el exhibicionismo de los participantes dispuestos a darlo todo de sí mismos. Por el otro, la existencia de un límite a su performance o la necesidad de un pudor que hay que vencer.

Todo este procedimiento llevado a cabo por la pantalla de TV determina en cierto sentido, una posterior producción de individuos en función de una determinada norma, que encierra en los aparatos de corrección determinados sujetos/máquina que comportan una domesticación de la vida bajo los parámetros salud/enfermedad que corrige la sociedad, organizando de tal forma un poder sobre la vida, sobre su prolongación y sobre su desarrollo.

Por otra parte programas como Policías en acción o 133: atrapados por la realidad dejan entrever que la televisión se encarga de mostrarnos en su lenguaje narrativo, el panoptismo existente en la época moderna, el cual hace referencia a la mirada totalizante de las cámaras de televisión. Estamos en presencia de una micro-vigilancia: "Curiosamente no se trata de una macro-vigilancia, sino de una micro-vigilancia en la superficie de la vida cotidiana" (Arancibia, 2006, p122).

El control policial es parte sustantiva de la denominada sociedad disciplinaria. El examen se presenta aquí como la instancia que combina: "Las técnicas de la jerarquía que vigila y las de la sanción que normaliza” (Foucault, 2005, p. 189).

De esta forma, la violencia aparece como un género fácil de contar y vender a un mercado mundial televisivo, gracias a su inteligibilidad inmediata y también a su capacidad de integrar sus códigos narrativos en cualquier contexto cultural. El dispositivo de microvigilancia es por un lado un mecanismo disciplinario y, por otro lado, un corrector de sanciones, de conductas impropias y de comportamientos desviados.

\section{La televisión: un mecanismo humano de producción de sentido}


Hannah Arendt de manera luminosa relata la preocupación por la acción y el mundo. Desde este punto de vista queda en plena evidencia que este mundo ya no es habitable para muchos. En este punto se origina otra situación que tiene que ver con la acción política. ¿Qué ocurre con la acción política? Aquella que como la define Arendt transforma el espacio público, que decide nuestra responsabilidad respecto de él, que incide en la definición de los asuntos comunes y que convierte en significativa la praxis por medio de la palabra (Berger, 2006). Estos son los tiempos de la desertización de lo público, un lugar donde las opiniones de los seres humanos han dejado de ser significativas y las acciones efectivas, lo que deviene la pérdida de un mundo habitable para todos.

No es casual que la narración ejercida por la televisión se construya sobre la vida de las personas, ya que su juicio esencial sucede sobre la realidad. De hecho, la televisión nos hace ser conscientes de la impotencia que padece muchas veces el hombre. La fórmula de la democracia, para la mayoría de las personas, pareciera identificada más bien en un principio de abandono sobre la vida común. Tal como señala Eduardo Santa Cruz: "En ese marco, la TV abierta opera de manera significativa en la escritura y construcción cotidiana de la realidad nacional, semantizando su instalación en los procesos universales y globales de desarrollo del capitalismo actual".

La circulación de imágenes de cuerpos por medio de la televisión, muestra cómo se articula la dimensión totalitaria, donde la parcelación del otro cuerpo implica la atomización de nosotros mismos, colocándose en escena una corta tolerancia comprometida sustancialmente con la ley. Las cuales inciden de manera determinante en el contexto vivido. "La televisión es considerada como una institución social ya que su producción y la mediación que establece con la audiencia, tiene una dimensión constitutiva, absolutamente específica, del orden social y cultural de la sociedad".

El lenguaje de la televisión narra dentro de la esfera de la sensibilidad del sujeto, elementos como explotación y dominio en el orden de lo cotidiano. Así, en su lenguaje, la televisión muestra el agotamiento de un modelo democrático en la sociedad contemporánea. Se delinea una silueta mínima del hombre en la renuncia de la democracia. Estas condiciones logran vivenciar elementos diversos de una manifestación comunicativa, que en su relato, reúne desde sus distintos ángulos las instancias de la democracia en su propia falta y en el derrumbe de su experiencia. Por tal, la televisión en nuestro tiempo no actúa ni como mera tecnología ni como sistema estético, sino como un mecanismo humano de producción de sentido. La comunicación humana no es un hecho individual sino social.

El cuerpo en sus aspectos más generales, deslinda con su acción más típicamente negativa de regímenes democráticos que le niegan la posibilidad de ser un sujeto presente en una comunidad. Quizá, la denominada democracia moderna sienta sus bases sobre la 
propia ausencia del vínculo social a la vida en común. Dentro de esta crítica general, esta crítica confusa, por añadidura, se encuentra la comunidad nacional despolitizada (Ranciere, 2005, p. 29). Una duplicidad entre el servicio social de proximidad y el rechazo absoluto del otro.

De este modo, se explicita y consolida la expresión de Rancière: "Esto implica un vuelco significativo de lo que es, de cierto modo, el fundamento de los derechos humanos" (2005, p. 29). Lo que en líneas generales sería, el viraje ético de la política.

\section{Referencias bibliográficas}

Agambem, Giorgio. (1998). Homo Sacer: El poder soberano y la nuda vida. Valencia: Editorial PreTextos. - (2001). Medios sin fin. Valencia: Ed. Pre -texto

Arancibia, Juan Pablo. (2006). Comunicación politica: Fragmentos para una genealogía de la mediatización en Chile. Santiago: Editorial Universidad ARCIS 2006.

Arendt, Hannah. (2005). ¿Qué es la política.? Buenos Aires: Editorial Paidós.

Baudrillard, Jean. (1989). De la Seducción. Madrid: Editorial Cátedra.

Cuadra, Álvaro. Zapping, Mercado y Virtualidad. Los contextos y Transcontextos Televisivos en la Era de la Globalización. En Revista investigación y crítica No 4.

Esposito, R. (2005). Immunitas: Protección y negación de la vida. Buenos Aires: Editorial Amorrortu.

Foucault, Micheal. (2005). Vigilary castigar. Buenos Aires: Editorial Siglo XXI.

González Requena, Jesús. (1999). El discurso televisivo. Madrid: Editorial Cátedra.

Nancy, Jean-Luc. (2006). El intruso. Buenos Aires: Editorial Amorrortu.

Rancière, Jacques. (1994). En los bordes de lo politico. Santiago: Editorial Universitaria.

Santa Cruz, Eduardo. (s. d.). «Un par de hipótesis sobre la TV abierta en Chile». Revista investigación y crítica № 4. 